University of Nebraska - Lincoln

DigitalCommons@University of Nebraska - Lincoln

Faculty Publications, Department of Psychology

Psychology, Department of

2014

\title{
Songs You Know by Heart: Alcohol, Promiscuous Sex, Drugs, and Escape in Jimmy Buffett's Music
}

\author{
Eve M. Brank \\ University of Nebraska-Lincoln, ebrank2@unl.edu \\ Kathleen A. Fox \\ Arizona State University, katefox@asu.edu \\ Victoria Kaspar \\ University of Nebraska College of Law, vkspar@live.com
}

Follow this and additional works at: https://digitalcommons.unl.edu/psychfacpub

Part of the Music Commons, and the Psychology Commons

Brank, Eve M.; Fox, Kathleen A.; and Kaspar, Victoria, "Songs You Know by Heart: Alcohol, Promiscuous Sex, Drugs, and Escape in Jimmy Buffett's Music" (2014). Faculty Publications, Department of Psychology. 974.

https://digitalcommons.unl.edu/psychfacpub/974

This Article is brought to you for free and open access by the Psychology, Department of at DigitalCommons@University of Nebraska - Lincoln. It has been accepted for inclusion in Faculty Publications, Department of Psychology by an authorized administrator of DigitalCommons@University of Nebraska - Lincoln. 


\title{
Songs You Know by Heart: Alcohol, Promiscuous Sex, Drugs, and Escape in Jimmy Buffett's Music
}

\author{
Eve M. Brank, ${ }^{1}$ Kathleen A. Fox, ${ }^{2}$ and Victoria Kaspar $^{3}$ \\ 1. Department of Psychology, University of Nebraska-Lincoln, Lincoln, Nebraska, USA \\ 2. School of Criminology and Criminal Justice, Arizona State University, Phoenix, Arizona, USA \\ 3. College of Law, University of Nebraska-Lincoln, Lincoln, Nebraska, USA
}

\begin{abstract}
Some researchers argue singer-songwriter Jimmy Buffett's lyrics focus on alcohol, promiscuous sex, and drugs, while others say Buffett's music has changed since he sold out to corporate sponsorship. Results from a systematic coding of all 386 of his songs released since 1969 indicate Buffett's music is more about escape and irony than deviant behaviors. Furthermore, lyric themes remain largely unaltered even through an increase in his popularity and corporate sponsorship.
\end{abstract}

Keywords: Jimmy Buffett, chronological development, lyrics

\section{Introduction}

Singer and songwriter Jimmy Buffett admits he pursued music primarily to meet women (Scaggs 2003), yet some say his faithful fan base resembles more of a religious sect (Ingersoll 2001; Mihelich and Papineau 2005) than a group of people following a guy on a whim. His lyrics are gratuitously cited or referenced in academic articles on topics as varied as the life review process (Jenko, Gonzalez and Seymour 2007), linguistics (Butcher 2005), the Endangered Species Act (Bogert 1994), human rights (Davey 2010), academic emergency medicine (Ledrick and Kuhn 2000), cosmetic surgery (Khunger 2015), botany (Wyatt 1998), pharmacy (Posey 2005), and cardiology (Dorros 2003). This seems to confirm Buffett's belief that his fans "are basically pretty normal people with a slight strain of insanity in their makeup" (Buffett 1992: 5). Those pretty normal people have tremendous purchasing 
power; the Jimmy Buffett brand graces a chain of restaurants, a Sirius Satellite radio station, beer, tequila, salsa, shoes, and margarita mixes - to name only a few.

The Buffett name is emblazoned on items for purchase, his lyrics are found in academic publications, and Jimmy Buffett's music and fans have been the topic of serious scholarly inquiries. For example, two academic journal articles (Bowen 1997; Mihelich and Papineau 2005) and a book chapter (Ingersoll 2001) have addressed some aspect of Jimmy Buffett's music or his fans. Another article demonstrated how his lyrics can teach criminology students about content analysis (Brank et al. 2009). The current research builds upon previous scholarly attention given to Jimmy Buffett, his music, and his fans by contributing to the literatures on popular culture and deviance in at least two important ways. First, given the research that examines the presence of deviant behaviour within popular music lyrics and videos (DuRant et al. 1997), the current study is among the first to assess the extent to which Buffett's music focuses on deviant behaviors (e.g., alcohol, promiscuous sex, and drugs) and whether outside forces such as corporate sponsorship influence these themes. Second, the present research is the first to conduct a systematic study of Jimmy Buffett's song lyrics using content analysis, which enables us to understand the underlying themes of Jimmy Buffett's lyrics (see Ballard and Coates 1995; Diamond, Bermudez and Schensul 2006; Miranda and Claes 2004).

\section{Who is Jimmy Buffett?}

James William Buffett was born in Mississippi in 1946. He spent his childhood in Mississippi and Alabama attending Catholic school because his parents hoped he would become a Jesuit priest (Buffett 1998). While attending college, Buffett learned to play the guitar from a fellow college student (Padgett 2013). After a brief career as a Billboard correspondent and a rocky recording start, Buffett released his first album in 1970 and since then has continued to record and release albums on a fairly regular basis. His music eludes classic categorization and instead is described as "yacht rock" or "gulf and western," which is a combination of calypso, salsa, and soul music (Nash 1990).

By his own admission, Buffett says he is not a great musician or singer, but he knows how to put on a show, and that is what keeps his fans interested (Vrabel 2013). His fans have also helped make him an accomplished book seller; he is one of only a few authors to have New York Times best sellers on both the fiction and nonfiction lists (Decurtis 1999). These fans are affectionately called Parrot Heads (or Parakeets for young fans), which is a name that organically originated from a comparison between Buffett's fans and the band Grateful Dead's Deadhead fans. Both fan bases attend concerts in droves. The Buffett fans, in a nod to Buffett's tropical-themed music, often dress in parrot-clad attire, thus, Parrot Heads. The Parrot Heads not only attend concerts but compose more than 200 not-forprofit civically and environmentally focused groups throughout the world. In 2015, the groups raised more than $\$ 3$ million dollars for organizations such as Make A Wish, Adopt A Manatee, and Toys for Tots. In addition, the members donated more than 200,000 volunteer hours (State of the Phlock 2016). 


\section{Previous scholarly attention to Jimmy Buffett's music and fans}

Jimmy Buffett's most famous song, "Margaritaville," has led innumerable fans to search for this famous place (Bowen 1997) that Buffett describes as "a state of mind" (Buffett 1992: 12). From a cultural geography perspective, Bowen examined this song, and other similar Buffett lyrics, to determine the role of Buffett's music in the construction of place, especially the mythical place of Margaritaville. Bowen explored Buffett's music by first examining a nonrandom sampling of some of Buffett's song lyrics that have a particular emphasis on place. Second, Bowen surveyed Buffett fans $(n=21)$ on a fan website. From her exploratory review of some of his lyrics, Bowen notes that Buffett's music often evokes a strong image of place but that escaping the realities of life is almost always the underlying theme. The small sample of Buffett fans confirmed this mental escapism to the fantasy place called Margaritaville that, ironically, becomes "tangible" in their minds.

Similarly, based on an internet ethnography of Jimmy Buffett fans, Mihelich and Papineau argue that Parrot Heads have created an oppositional culture. This subculture of fans desire to escape their regular corporate lives into a life of sailing, drinking, having sex, and going to the beach. The irony, as Mihelich and Papineu observe, is that the Parrot Head tequila- and beer-swilling activities directly support the mega-corporate endeavors of Jimmy Buffett. While Jimmy Buffett has done a remarkably good job of preaching the need for a carefree life, he is an extremely hardworking entertainer. Of course, this oxymoronic message has not been ignored by all of his fans; some fans completely condemn Buffett for his corporate achievements. For example, Mihelich and Papineu found that The Church of Buffett, Orthodox (COBO) fan website was particularly pejorative in denouncing Buffett's commercialism. Indeed, fans on the COBO website differentiate between Buffett's albums after and prior to the 1977 release of Changes in Latitudes, Changes in Attitudes. This album's release, the fans say, was the start of a "Corporitaville" focus that mirrors too closely the capitalism underlying the "rat race" Buffett fans are trying to escape.

Although Buffett's faithful Parrot Heads say they love his reggae/country music because of the escape it provides for them, Ingersoll compared their fanaticism to that of a religious experience. A Jimmy Buffett concert, and the fans who attend those concerts, are seemingly irreligious or even antireligious; however, Ingersoll (2001) notes that "Parrot Headism" functions much like a traditional religion for some Buffett fans because of the philosophical, mystical, and ritual similarities between the two experiences. For example, a belief in a utopian paradise (Margaritaville) and ritualistic behaviours (pilgrimages to concerts) certainly have religious undertones, and according to Ingersoll, being a Parrot Head fulfills the human need for meaning, purpose, ritual, community, and transcendent experiences.

Taken together, the research by Bowen, Mihelich, and Papineau, and Ingersoll suggest that Jimmy Buffett, his music, and his fans glorify promiscuous sex, drugs, alcohol, and escape while openly deriding traditional religion and modern culture. Additionally, some fans argue that despite his carefree beach-themed rhapsodies, Jimmy Buffett is a savvy businessman selling his Parrot Heads whatever they will buy (Decurtis 1999). To note, none of these authors systematically examined Jimmy Buffett's lyrics. In each instance, the authors examined either convenience samples on internet fan websites (Bowen 1997; Mihelich and Papineau 2005) or handpicked songs to exemplify the authors' arguments 
(Bowen 1997; Ingersoll 2001). Indeed, systematically examining an artist's lyrics in their entirety is quite rare (Hilbert 2012), yet understanding how musicians develop throughout their careers is an important endeavor (Collins 2012; Punter 2014). The current research examines some of the same issues as these previous researchers as well as additional questions through systematically content analyzing all of Jimmy Buffett's song lyrics.

\section{Current research}

Based on the research by Michelich and Papineau (2005), the current project seeks to examine whether the "ultimate dream lifestyle" (180) of "drinking, sex, and getting away from it all" (185) is truly a consistent theme in Jimmy Buffett's music. Similarly, Ingersoll (2001: 255) stated that Buffett "glorifies sex and drugs" and "openly derides traditional religion." Furthermore, Bowen's survey respondents also emphasized escape to a better life in their interpretation of the place of Margaritaville. Therefore, the current content analysis examines Buffett's lyrics for a focus on alcohol, promiscuous sex, drugs, escapism, and religion.

We compare the content of Jimmy Buffett's lyrics from different time periods based on potentially influential changes within his career. Given that some research suggests that Buffett's music became more commercialized after 1977 when his album Changes in Latitudes, Changes in Attitudes hit the pop music charts, we examine both the themes of Buffett's songs throughout his career and also compare songs before and after 1977 (Ingersoll 2001; Michelich and Papineau 2005). Furthermore, comparisons are made before and after 1984 when Buffett obtained corporate sponsorship from Grupo Modelo, the company that produces Corona beer among other beers (Michelich and Papineau 2005). In addition to the potential chronological effects, we also examined the extent to which individual song content was affected by its popularity (measured by song chart history). For example, Buffett's music may be viewed as focusing on deviant behaviors because the songs that have become popular are the ones that glamorize alcohol, promiscuous sex, and drugs.

\section{Methods}

\section{Data: Jimmy Buffett songs}

The discography listed on Jimmy Buffett's official Margaritaville website was used to create the population of songs analyzed. In total, the discography lists 490 different songs from 48 Jimmy Buffett albums (51 albums if the Boats, Beaches, Bars, and Ballads boxset is counted as four separate albums). The website discography contains a number of repeated songs and does not contain all of Buffett's songs. For example, the website discography does not include a few compilation albums such as Calaloo and Summerzcool (two songs not on other albums) and Live at Texas Stadium (album in conjunction with George Strait and Alan Jackson; seven songs sung by or with Jimmy Buffett; three of those were new); we included new songs from such albums in our analysis. The discography also does not include special corporate releases such as Calaloo, an Extended Play (EP) released exclusively at Best Buy stores, or songs Buffett performed or wrote for movie soundtracks, such as "Purple People Eater" from the Contact soundtrack. Again, we include these songs in our research. 
Two albums included on the discography, Songs You Know by Heart (13 songs; and the inspiration for the title of the current article) and Meet Me in Margaritaville (38 songs on two discs) were greatest hits albums and did not include any new songs; therefore, these albums were not included in our analysis. A few other live or compilation albums (e.g., Buffett Live: Tuesdays, Thursdays, Saturdays and Boats, Beaches, Bars, and Ballads) included on the website discography had mostly previously released songs but did also include some new releases; new songs were included in our population of songs.

After removing rereleased songs, a song entirely in Spanish that was also released in English, and instrumental-only songs; and including hidden tracks, single releases, songs from soundtracks, and songs from albums done with other artists, there were 386 songs compiled from 46 different albums (or 49 if Boats, Beaches, Bars, and Ballads are counted as four albums). For those albums that were either soundtracks (Rancho Deluxe and Hoot) or in conjunction with other artists (Live at Texas Stadium), only those songs written or performed by Jimmy Buffett were included. Albums/songs were released from 1969 through 2015. ${ }^{1}$

\section{Procedure: coding the songs}

An independent research assistant unaware of the research questions coded each of the 386 songs, and the first author coded 20 percent of those songs in order to establish an acceptable level of inter-rater reliability. On tested key variables, the two coders had high agreement (range of Cohen's $\kappa=.88$ to 1.0) with disagreements being resolved through discussion. The high agreement rating may be attributed to the researchers' extensive training and the decision to conservatively code the songs based on manifest content. For instance, the song "Brown-Eyed Girl" was coded as not having any drug references despite some speculation that when Van Morrison wrote the song he was referring to drugs and drug paraphernalia in the lyrics. Certainly, lyrics may have double or obscure meanings, but we chose to extract the simplest and most explicit meaning in order to avoid potentially ambiguous content and because we wanted to code the meaning that most people understand when they hear the songs.

Coders recorded basic descriptive information about the songs such as the album on which the song first appeared, what year that album was released, whether Buffett was a writer of the song, whether the song was written in first-person, whether the song charted, and how high it charted. Next, the coders focused on coding the lyrics by recording the general theme of the song. Based loosely on the categories outlined by Cole (1971), the songs were categorized into one of four different themes (love/sex, political statement/social protest, humor/storytelling, and violence/alcohol/drugs). For instance, the song "All the Ways I Want You" was categorized as a love/sex song and the song "Bend a Little" was coded as political statement/social protest song. The "Coconut Telegraph" song was coded as humour/storytelling and "God's Own Drunk" was coded as a song that focused primarily on violence/alcohol/drugs.

The coders also recorded information about whether, how many times, and in what way the song lyrics referenced sex, violence, drugs, alcohol, and illegal behavior. We followed a similar coding technique as Herd $(2005,2008)$ for alcohol and drugs so that references could be direct or indirect to drinking and using drugs (i.e., binge drinking, drinking 
contexts such as bars, and altered states such as being drunk or high). For example, the song "Pencil Thin Mustache" includes the line that says "but only jazz musicians were smoking marijuana" and another line that says "but all you want to do is learn how to score." The coders noted that this song had a reference to drugs (specifically marijuana) and a reference to sex. As another example, "Bama Breeze" references alcohol: "you can drink some beer down there" and other illegal behavior: "lets the ladies in free with the fake I.D." The song "Cuban Crime of Passion" describes a jilted lover who was so distraught that "he pulled a knife and took poor Danny's life," which was coded as violence (specifically, murder). To continue the theme of illegal or illicit behavior, sexual references were further examined and coded as occurring in either promiscuous or not promiscuous situations. For example, "Frank and Lola" contained one sexual reference, but as it was in the context of repairing a marriage, the song was coded as not promiscuous. "Permanent Reminder of a Temporary Feeling," however, also contains one sexual reference but in the context of a one-night stand and an unplanned pregnancy. This song was therefore coded as promiscuous.

Additionally, based on the work of Diamond and colleagues (2006), the coders noted whether or not the references glamorized violence, drugs, alcohol, and illegal behavior. For example, if the song referenced taking drugs in a positive way, then it was coded as glamorizing drug use. In the song "Summerzcool," Buffett glamorizes alcohol by singing about what will be taught at the school: "Beer 101."

Consistent with prior research, the coders recorded whether the song referred to escaping or getting away from reality (Bowen 1997; Mihelich and Papineau 2005). For example, "Holiday" refers to taking a holiday to a "far off wonderland." In "Island," Buffett sings that "maybe someday I'll have the means to reach your distant shores."

Because of the attention to Buffett's corporate endeavors, we also coded the lyrics for references to name-brand products. Borrowing a similar methodology of Martin and Collins's (2002) content analysis of music videos, presence of name-brand products was coded as either present or not in the song lyrics. For example, in "The Great Filling Station Holdup" the lyrics include "a can of STP" (fuel additive) and "sitting in a Krystal" (fast food restaurant). Additionally, the song "Frank and Lola" mentions "Junior Mints" (candy).

Although Ingersoll presents a convincing comparison between Buffett fandom and religious practice, she states that Buffett has an "irreverent tone and occasional hostility toward religion" (2001: 255). Thus, religion was coded as being mentioned or not and, if mentioned, the lyrics were coded as referencing religion in a derogatory way or not. In the song, "My Head Hurts, My Feet Stink, and I Don't Love Jesus," Buffett sings religiously derogatory lyrics that are the same as the title of the song, and the song was coded as both mentioning religion and doing so in a derogatory way.

\section{Results}

The results are presented in three main parts. First, we describe Jimmy Buffett songs and

their themes. Second, we describe the extent to which deviant behavior, product/brand 
placement, religion, and escape are present in the songs. Third, we examine these same characteristics dependent on song popularity, corporate sponsorship, and song writer.

\section{General song information}

Jimmy Buffett wrote $71.24 \%(n=275)$ of the 386 songs. Thirty songs $(7.77 \%)$ charted on the Adult Contemporary Chart, Hot Country Singles, or Billboard Hot 100. Two songs (less than $1 \%$ ) reached the number one position ("Margaritaville" and "It's Five O'Clock Somewhere"). More than half $(58.03 \% ; n=224)$ of the songs were coded as having a humour/storytelling theme. Almost one-third $(23.31 \% ; n=90)$ of the songs were love/sex-themed songs, $15.02 \%(n=58)$ were a political statement/social protest-themed song, and $3.11 \%(n=12)$ were about violence/alcohol/drugs. The majority of the songs $(83.68 \% ; n=323)$ were written from the first-person perspective (see Table 1).

Table 1. General song information

\begin{tabular}{lcc}
\hline Variable & Percentage of songs & Number of songs $(n=386)$ \\
\hline Buffett as writer & $71.24 \%$ & 275 \\
Charted & $7.77 \%$ & 30 \\
Theme: Storytelling/humor & $58.03 \%$ & 224 \\
Theme: Love/sex & $23.32 \%$ & 90 \\
Theme: Political statement/social protest & $15.03 \%$ & 58 \\
Theme: Violence/alcohol/drugs & $3.11 \%$ & 12 \\
First-person perspective & $83.68 \%$ & 323 \\
\hline
\end{tabular}

\section{Specific lyric information}

Alcohol, sex, drugs, and illegal behavior

Approximately one-fourth $(26.68 ; n=103)$ of the songs had some reference to alcohol, $7.51 \%(n=29)$ referenced sex, and $6.74 \%(n=26)$ referenced drugs. These percentages are reduced when we examine the tone of the lyrics. As mentioned above, coders not only coded the presence of these topics but also coded for glamorization. Based on the operational definition described above, 9.84\% $(n=38)$ of the songs glamorized alcohol, $2.33 \%$ $(n=9)$ glamorized drugs, and of the 29 songs that referenced sex, $25(86.21 \%)$ referenced promiscuous sex (see Table 2). The most common type of alcohol mentioned in the songs was beer $(5.18 \% ; n=20)$, next was rum $(3.63 \% ; n=14)$, and then wine $(3.11 \% ; n=12)$. The remaining 57 songs $(n=15 \%)$ mentioned either multiple types of alcohol, general drinking of alcohol, or a variety of other types of alcohol (e.g., gin, whiskey). The most common type of drug mentioned in the songs was marijuana $(5.18 \% ; n=20)$. Illegal behavior generally (not including drugs) was mentioned in 25 songs (6.48\%), but glamorized in only seven songs $(1.81 \%)$. The most common type of illegal behavior mentioned was theft/robbery $(2.59 \% ; n=10)$. Some of the other types of illegal behavior included underage drinking $(0.78 \% ; n=3)$, bootlegging/drug running $(0.78 \% ; n=3)$, and prostitution $(0.78 \% ; n=3)$. 


\begin{tabular}{lcc}
\hline Table 2. Specific lyric information & & \\
\hline Variable & Percentage of songs & Number of songs $(n=386)$ \\
\hline Alcohol mentioned & $26.68 \%$ & 103 \\
Alcohol glamorized & $9.84 \%$ & 38 \\
Sex mentioned & $7.51 \%$ & 29 \\
Promiscuous sex & $6.48 \%$ & 25 \\
Drugs mentioned & $6.74 \%$ & 26 \\
Drugs glamorized & $2.33 \%$ & 9 \\
Illegal behavior mentioned & $6.48 \%$ & 25 \\
Illegal behavior glamorized & $1.81 \%$ & 7 \\
Violence mentioned & $8.81 \%$ & 34 \\
Violence glamorized & $1.04 \%$ & 4 \\
Brand-name items mentioned & $17.62 \%$ & 68 \\
Religion & $13.47 \%$ & 52 \\
Derogatory about religion & $2.85 \%$ & 11 \\
Escape & $43.01 \%$ & 166 \\
\hline
\end{tabular}

Brand names, religion, and escape

Of the 386 songs, 68 (17.62\%) mentioned some sort of brand-named item or product. Fiftytwo songs $(13.47 \%)$ mention religion or reference to religious notions; eleven $(2.85 \%)$ of those songs did so in a derogatory way. Almost half of the songs $(43.01 \% ; n=166)$ referenced some sort of escape or "getting away" (see Table 2). For those songs that did mention escape, most did not mention alcohol $(66.27 \% ; n=110)$ or drugs $(90.96 \% ; n=151)$.

\section{Popularity, "Corporitaville," and Jimmy's own voice}

Michelich and Papineau highlighted some of the fans' opposition to Buffett's corporate focus as his popularity grew. While Jimmy Buffett continues to sing about "drinking, sex, and getting away from it all," his own life contrasts with that as he has grown in popularity (Michelich and Papineau 2005). We conducted a series of comparisons to determine if changes in Buffett's music was distinguishable based on the following factors: (1) time period effect from the popularity of his Changes in Latitudes, Changes in Attitudes album (1977 and before versus post-1977) and chart popularity (songs that charted versus songs that did not chart), (2) corporate sponsorship effect (1984 and before versus post-1984), and (3) song writer (songs written by Buffett versus those written by others). For each of the four factors we compared lyric emphasis on alcohol, sex, drugs, escape, product/brand placement, and religion.

Popularity after Changes in Latitudes album and chart popularity

The 386 songs were divided into songs released prior to the Changes in Latitudes album $(21.24 \% ; n=82)$ and those after the album's release $(78.76 \% ; n=304)$. The Changes in Latitudes album was included in the prior time period because the claim is that the popularity of this album was a defining moment, and change came after its popularity (Ingersoll 2001; Michelich and Papineau 2005). Jimmy Buffett was more often a writer on the songs before $(85.37 \% ; n=70$ out of 82$)$ compared to after Changes in Latitudes $(67.43 \% ; n=205$ out of 
304). ${ }^{2}$ Songs after Changes in Latitudes were also less likely to mention alcohol $(22.70 \% ; n=69)$ than before $(41.46 \% ; n=34)$, and less likely to mention drugs $(4.93 \% ; n=15)$ than before $(13.41 \% ; n=11)$. A slightly higher percentage of songs $(9.76 \% ; n=8)$ charted prior to the release of Changes in Latitudes than after $(7.24 \% ; n=22)$. No other comparisons resulted in appreciable differences.

One explanation for the fan and research focus on alcohol, drugs, and escape may be due to the increased prevalence of these topics in Jimmy Buffett's songs that have received chart acclaim. To determine if this is true we compared songs that charted (any placement on Adult Contemporary, Hot Country Singles, or Billboard Hot 100) to those that did not. Of the 30 songs that charted, almost half $(46.67 \% ; n=14)$ mention alcohol whereas only $25.0 \%$ of the noncharting songs mention alcohol ( $n=89$ of 356 uncharted songs). Similarly, a greater proportion of charting songs mention drugs $(20.0 \% ; n=6)$ than in those songs that did not chart (5.62\%; 20 of 356 uncharted songs). The same pattern emerges for sex, with $23.33 \%(n=7)$ of charting songs mentioning sex and only $6.18 \%(n=22$ of 356$)$ of noncharting songs mentioning sex. The rest of the comparisons (e.g., religion, escape) did not have noticeable differences between charting songs and noncharting songs.

Corporate sponsorship

Did something happen to Jimmy Buffett's music after he gained corporate sponsorship from Grupo Modelo in 1984? To answer this question we divided the songs into two time periods: release date prior to and including 1984 versus release date after 1984. Jimmy Buffett was more likely to be a writer on a song prior to the corporate sponsorship $(83.33 \% ; n=120)$ than after the corporate sponsorship $(64.05 \% ; n=155)$. Alcohol was more likely to be mentioned before $(37.50 \% ; n=54)$ than after $(20.25 \% ; n=49)$. Similarly, drugs were mentioned more before $(11.81 \% ; n=17)$ than after corporate sponsorship $(3.72 \% ; n=9)$. No other noteworthy differences were present. None of these trends are different from the trends observed for the comparison of songs prior and after the Changes in Latitudes success.

Buffett as song writer

Songs were divided into two categories to determine if Buffett's reputation was attributed to singing his own songs versus those written by others (i.e., by other band members or songs that were cover songs). Jimmy Buffett wrote in whole or in part $71.24 \%$ of the songs $(n=275)$. Escape was a more common component in those songs written by Buffett $(45.09 \%$; $n=124)$ than those written by others $(37.84 \% ; n=42)$. No other differences were noticeable between the songs written by Buffett and those not written by him.

\section{Discussion}

Previous researchers (Ingersoll 2001; Michelich and Papineau 2005) have stated that Buffett and his music are about celebrating drinking, promiscuous sex, drugs, and getting away from it all. Even Buffett himself acknowledged this belief in the words from Today's Message (a mock sermon included on the album Feeding Frenzy) when he says, "some peabrained people think that some of my songs are obscene and nasty. But we know better don't we?" Based on the current lyric content analysis, Buffett may be right. The current 
analysis demonstrates that Buffett does not sing about deviant topics as much as commonly believed. Although one quarter of Buffett's songs mentioned alcohol, only a small proportion of the songs focused on alcohol, drugs, or promiscuous sex, and far fewer glamorized these activities. The current content analysis demonstrated that songs that charted were more likely to mention alcohol, drugs, and sex than those that did not chart. The discrepancy between perceived and real references to deviant behaviors may be attributed to the nature of his more popular songs, which says less about Buffett and more about those who listen to his music and make it popular.

Jimmy Buffett's level of focus on alcohol and drugs is quite similar to other types of music. For example, DuRant and colleagues (1997) examined how often alcohol was present in a sample of approximately 500 music videos and found that nearly one-fourth of the videos displayed or portrayed alcohol. In a similar study examining 359 music videos, Gruber et al. (2005) recorded alcohol presence in 34\% of their sample. Rap/hip-hop music videos had a significantly higher proportion (56\%) than did the rock, rhythm and blues, or pop $(27 \%, 26 \%$, and $27 \%$, respectively). Drugs were present in $31 \%$ of the rap/hip-hop videos, $9 \%$ of the rock videos, $4 \%$ of rhythm and blues videos, and not present in the pop videos sampled.

Furthermore, of the 490 "gangsta rap" songs that Armstrong (2001) content analyzed, $22 \%$ had violent and misogynist lyrics, and of the 403 rap song lyrics examined by Kubrin (2005), approximately 65\% referenced violence. Similarly, Martin and Collins (2002) examined violence and brand/product placement in music videos and found that violence was present in approximately $15 \%$ of the 191 videos they sampled. Although they did not provide the percentage of videos that included brand placement, they found that products such as tobacco, weapons, sunglasses, telephones, and cars were associated with personal violence. Alcohol and drug references and the glamorization of these activities increased in rap music lyrics during a similar time period as the songs included in the current research (Herd 2005, 2008).

Why has there been more research attention on violence in rap music compared to singers such as Jimmy Buffett, when Buffett's music clearly has references to violence? The focus on violence in rap music over other genres may be due to the type of violence and the explicit nature of the violence described, or as Binder (1993) suggests, it could be due to the social framing of a particular musical genre. As she demonstrated, both rap and heavy metal music had references to sex and rebelliousness, yet the media's framing of the two genres was quite different because of racial undertones. Binder argues that this framing is due to the racial stereotypes and cultural undertones of rap versus heavy metal fans. As noted by Ingersoll, Jimmy Buffett fans are almost exclusively white, which might explain why the idea of violence in his songs has been overlooked. Yet violence was mentioned in his lyrics more often than sex or drugs.

Although alcohol, drugs, and sex were not as frequently present in Jimmy Buffett's music as what might be popularly believed, the notion of escape or a better life was quite common. Almost half of his songs reference escape or a better life in some way. This escape, however, is not often in relation to alcohol or drugs. Most often, escape was portrayed as a form of a vacation, a trip to an island, or simply a statement about getting away from a situation. 
Through our systematic content analysis, we have a better understanding of the message Jimmy Buffett sends with his lyrics. Future research may benefit by examining the effects of Jimmy Buffett's messages on those who listen to his music. Examining the extent to which Buffett's fans engage in the behaviors described in his lyrics may lead to important information about the relationship between popular music and resulting behavior. It might also be useful to submit Jimmy Buffett's lyrics to a systematic computer analysis. For example, West and Martindale (1996) examined the content of lyrics from 183 Beatles songs employing the two computer programs of LEXSTAT and COUNT. Their analysis examined artistic evolution and found that the Beatles lyrics became more novel and complex over time. Such objective measures of word length and word repetition may contribute to our understanding of Buffett's artistic evolution.

\section{Conclusion}

Music has become a part of our cultural experience and, in a time when most artists produce only one or a few hit songs, a singer/songwriter like Jimmy Buffett is a rarity. For more than 45 years Jimmy Buffett has been writing and singing. He has certainly developed from relative obscurity - his first album in 1970 sold 324 copies (Scaggs 2003) - to a well-known music icon. Throughout that time his songs have often told stories that take his fans "somewhere other than here" ("The Great Filling Station Holdup," 1973). But he also sings a great deal about love, relationships, and family. Despite claims that his fame, popularity, and corporate sponsorship altered his music, our results demonstrate that his lyrics have been more consistent than changing.

Acknowledgments - The authors would like to thank Richard Harb, Kyle McNeal, Tasha Youstin, and Lee Boeppler for their contributions to this research. This manuscript is dedicated to the first author's husband, Adam, who helped her find "Love in the Library" more than 20 years ago and to their daughter, Mabry, who will always be "Little Miss Magic" no matter how old she gets.

\section{Notes}

1. Songs included only on concert videos such as Live by the Bay and Millennium Concert were not included. Also not included are songs only sung on radio shows ("Lawyer and the Asshole," "Please Take Your Drunk 15 Year Old Girlfriend Home") and rare albums with unavailable lyrics (Live at Lulu's).

2. Given that the analyses are based on the population rather than the sample of Jimmy Buffett songs, we did not perform inferential tests.

\section{References}

Armstrong, E. G. 2001. “Gangsta Misogyny: A Content Analysis of the Portrayals of Violence against Women in Rap Music." Journal of Criminal Justice and Popular Culture 8/2: 96-126.

Ballard, M. E., and S. Coates. 1995. "The Immediate Effects of Homicidal, Suicidal, and Nonviolent Heavy Metal and Rap Songs on the Moods of College Students." Youth and Society 27/2: 148-68. http://dx.doi.org/10.1177/0044118X95027002003

Binder, A. 1993. "Constructing Racial Rhetoric: Media Depictions of Harm in Heavy Metal and Rap Music." American Sociological Review 58/6: 753-67. http://dx.doi.org/10.2307/2095949 
Bogert, L. M. 1994. “That's My Story and I'm Stickin' to It: Is the 'Best Available' Science any Available Science under the Endangered Species Act?" Idaho Law Review 31/1: 85-150.

Bowen, D. 1997. “Lookin' for Margaritaville: Place and Imagination in Jimmy Buffett's Songs." Journal of Cultural Geography 16/2: 99-109. http://dx.doi.org/10.1080/08873639709478339

Brank, E. M., K. A. Fox, T. J. Youstin, and L. C. Boeppler. 2009. "Changing the Latitudes and Attitudes about Content Analysis Research." International Journal of Teaching and Learning in Higher Education 20/4: 476-80.

Buffett, J. 1992. The Parrot Head Handbook. Los Angeles: MCA Records. 1998. A Pirate Looks at Fifty. New York: Random House.

Butcher, C. A. 2005. “The Case against the 'Native Speaker'."English Today 21/2: 13-24. http://dx.doi .org/10.1017/S0266078405002038

Cole, R. R. 1971. "Top Songs in the Sixties: A Content Analysis of Popular Lyrics." American Behavioral Scientist 14: $389-400$.

Collins, M. 2012. "Sucking in the Seventies? The Rolling Stones and the Aftermath of the Permissive Society." Popular Music History 7/1: 5-23.

Davey, M. 2010. "Pirate Looks at the Twenty-First Century: The Legal Status of Somali Pirates in an Age of Sovereign Seas and Human Rights." Notre Dame Law Review 85/3: 1197-1230.

Decurtis, A. 1999. "Music; Jimmy Buffett, Traveling Salesman of Leisure." New York Times, 21 February. http://www.nytimes.com/1999/02/21/arts/music-jimmy-buffetttraveling-salesman-of-leisure.html (accessed 9 May 2016).

Diamond, S., R. Bermudez, and J. Schensul. 2006. "What's the Rap about Ecstasy? Popular Music Lyrics and Drug Trends among American Youth." Journal of Adolescent Research 21/3: 269-98. http://dx.doi.org/10.1177/0743558406287398

Dorros, G. 2003. "Carotid Stenting: Changes in Attitude and Changes in Latitude." Catheterization and Cardiovascoular Interventions 59/3: 415-16. http://dx.doi.org/10.1002/ccd.10566

DuRant, R. H., E. S. Rome, M. Rich, E. Allred, J. S. Emans, and E. R. Woods. 1997. “Tobacco and Alcohol Use Behaviors Portrayed in Music Videos: A Content Analysis." American Journal of Public Health 87/7: 1131-35. http://dx.doi.org/10.2105/AJPH.87.7.1131

Gruber, E. L., H. M. Thau, D. L. Hill, D. A. Fisher, and J. W. Grube. 2005. “Alcohol, Tobacco and Illicit Substances in Music Videos: A Content Analysis of Prevalence and Genre." Journal of Adolescent Health 37/1: 81-83. http://dx.doi.org/10.1016/j.jadohealth.2004.02.034

Herd, D. 2005. "Changes in the Prevalence of Alcohol Use in Rap Song Lyrics, 1979-1997." Addiction 100/9: 1258-69. http://dx.doi.org/10.1111/j.1360-0443.2005.01192.x

_. 2008. "Changes in Drug Use Prevalence in Rap Music Songs, 1979-1997." Addiction Research and Theory 16/2: 167-80. http://dx.doi.org/10.1080/16066350801993987

Hilbert, M. 2012. "When I Becomes We: How Prototypically "Pop" Are a Band's Lyrics after One Breakup and Two Reunions?" Popular Music History 7/2: 159-84.

Ingersoll, J. J. 2001. "The Thin Line between Saturday Night and Sunday Morning." In God Is in the Details: American Religion in Popular Culture, ed. E. M. Mazur and K. McCarthy, 253-66. London: Routledge.

Jenko, M., L. Gonzalez, and M. J. Seymour. 2007. "Life Review with the Terminally Ill." Journal of Hospice and Palliative Nursing 9/3: 159-67. http://dx.doi.org/10.1097/01.NJH.000 0269995.98377.4d

Khunger, N. 2015. "Briding the Generation Gap: Dilemmas of a Cosmetic Surgeon." Journal of Cutaneous and Aesthetic Surgery 8/1:1-2. http://dx.doi.org/10.4103/0974-2077.155059 
Kubrin, C. E. 2005. "Gangstas, Thugs, and Hustlas: Identity and the Code of the Street in Rap Music." Social Problems 52/3: 360-78. http://dx.doi.org/10.1525/sp.2005.52.3.360

Ledrick, D., and W. Kuhn. 2000. “Two Plus Two.” Academic Emergency Medicine 7/11: 1336. http://dx .doi.org/10.1111/j.1553-2712.2000.tb00487.x

Martin, B. A. S., and B. A. Collins. 2002. "Violence and Consumption Imagery in Music Videos." European Journal of Marketing 36/7-8: 855-73. http://dx.doi.org/10.1108/03090560210430845

Mihelich, J., and J. Papineau. 2005. "Parrotheads in Margaritaville: Fan Practice, Oppositional Culture, and Embedded Cultural Resistance in Buffett Fandom." Journal of Popular Music Studies 17/2: 175-202. http://dx.doi.org/10.1111/j.1524-2226.2005.00041.x

Miranda, D., and M. Claes. 2004. "Rap Music Genres and Deviant Behaviors in French-Canadian Adolescents." Journal of Youth and Adolescence 33/2: 113-22. http://dx.doi.org/10.1023/B:JOYO .0000013423 .34021 .45

Nash, A. 1990. “Jimmy Buffett's Parrot Heads.” Entertainment Weekly. http://www.ew.com/article/ 1990/07/13/jimmy-buffetts-parrot-heads (accessed 9 May 2016).

Padgett, C. S. 2013. "Jimmy Buffett." Encyclopedia of Alabama. http://www.encyclopediaofalabama .org/article/h-1219

Posey, L. 2005. “Managing Risk." Journal of the American Pharmacists Association 45: 15-16. http://dx.doi .org/10.1331/1544345052843002

Punter, D. 2014. "Dylan and Pity." Popular Music History 8/2: 141-54. http://dx.doi.org/10.1558/ pomh.v8i2.141

Scaggs, A. 2003. “Jimmy Buffett." Rolling Stone, 18 September: 931.

State of the Phlock. 2016. "About PHIP." Parrot Heads in Paradise, Inc. www.phip.com (accessed 9 May 2016).

Vrabel, J. 2013. "A Conversation with Jimmy Buffett." Time, 19 August. http://entertainment.time .com/2013/08/19/a-conversation-with-jimmy-buffett/ (accessed 9 May 2016).

West, A., and C. Martindale. 1996. "Creative Trends in the Content of Beatles Lyrics." Popular Music and Society 20/4: 103-125. http://dx.doi.org/10.1080/03007769608591647

Wyatt, R. 1998. "Richards II: Some Things Do Remain Quite the Same." American Journal of Botany 85/10: 1502-505. http://dx.doi.org/10.2307/2446405

\section{Author Biographies}

Eve M. Brank is an associate professor of psychology and courtesy professor of law in the LawPsychology program at the University of Nebraska, Lincoln. Her research focuses primarily on the way the law intervenes in personal and family decision making. Contact: 334 Burnett Hall, University of Nebraska-Lincoln, PO Box 880308, Lincoln, NE 68588-0308 USA, email ebrank2@unl.edu

Kathleen A. Fox is an associate professor in the School of Criminology and Criminal Justice at Arizona State University. Her research focuses primarily on crime victimization, including theoretical tests, the gang-victimization link, and the effects of victimization on fear of crime and protective behavior. Contact: Arizona State University School of Criminology and Criminal Justice, 411 N. Central Ave., Phoenix, AZ 85004 USA, email katefox@asu.edu

Victoria Kaspar recently completed her first year at the University of Nebraska College of Law. She graduated from the University of Nebraska-Lincoln in 2015 with a degree in psychology, English, and political science. While there, she was a research assistant in the Psychology Department's Law and Policy Lab. Contact: 334 Burnett Hall, University of Nebraska-Lincoln, PO Box 880308, Lincoln, NE 68588-0308 USA, email vkspar@live.com 